\title{
Self Medication Practice among Iraqi Patients in Baghdad City
}

\author{
Ali L. Jasim ${ }^{1, *}$, Taqua A. Fadhil ${ }^{1}$, Salam S. Taher ${ }^{2}$ \\ ${ }^{1}$ Assistant lecturers in clinical pharmacy department, College of Pharmacy, Baghdad University \\ ${ }^{2}$ Postgraduate pharmacist in clinical pharmacy department, College of Pharmacy, Baghdad University \\ *Corresponding author: alilateef_81@yahoo.com
}

Received January 07, 2014; Revised January 22, 2014; Accepted February 07, 2014

\begin{abstract}
The practice of self medication is continuously increasing worldwide due to its important roles in curing minor conditions or symptoms. This study was conducted to evaluate the factors associated with self medication practice of Iraqi respondents residing in Baghdad City. This study was designed as cross sectional study in which data was collected via direct interviews with respondents using a previously prepared questionnaire. This study investigated 348 respondents from different age groups. The majority of respondents were male aged between 30-60 years, married with secondary or academic level of education and employed with accepted monthly income. The main reas on for practicing self medication was previous experience with the same condition followed by considering the current condition simple with no need to consult a physician. A previous prescription was revealed to be the commonest source of information about the self medicated drugs followed by community pharmacies and family members or friends. Flu or common cold was the commonest indication identified for self medication followed by headache, back or muscle pain, dyspepsia, diarrhea and others. Drugs used in treating these conditions were antibiotics, the commonest, followed by paracetamol, antihistamines, non-steroidal anti-inflammatory drugs, cough preparations, antispasmodics, skeletal muscle rela xants, antacids, antidiarrheals and others.
\end{abstract}

Keywords: selfmedication, Iraqi respondents, minor conditions

Cite This Article: Ali L. Jasim, Taqua A. Fadhil, and Salam S. Taher, "Self Medication Practice among Iraqi Patients in Baghdad City.” American Journal of Pharmacological Sciences, vol. 2, no. 1 (2014): 18-23. doi: 10.12691/ajps-2-1-4.

\section{Introduction}

In recent years there has been an increasing trend in self medication practice in both developed and developing countries [1]. Self medication is defined as obtaining and utilizing medications or herbs with no supervision of the physician for diagnosis, prevention or treatment of minor symptoms or conditions [2], or the use of previously prescribed drugs either continuously or intermittently for chronic or recurrent disease or symptom [3]. Self medication has important roles in the care of minor ailments and symptoms [4].

Different patterns of self medication exist in different populations and these patterns are effected by factors like age, gender, medical knowledge, level of education and income [5].

Self medication makes economic savings for national health care systems and put more responsibility on individual patients in managing their conditions in well educated manner [6].

Although self medication practice is common in both developing and developed countries, higher degree of prevalence was found in the developing world $[7,8,9]$. The higher degree of prevalence in the developing countries could be attributed to many causes such as the ability to obtain wide range of drugs over the counter, poor regulatory practices, limited access to health care facilities $[10,11]$ and the availability of illegal sellers of medications (market sellers and non professional administrators of injectable drugs) [12].

Many studies were done about self medication practice, yet the majority of these studies were conducted in countries differing from Iraq regarding the nature of health care system and culture. Therefore, results of these studies cannot be transferred completely to the Iraqi context.

This study was aimed to evaluate the factors associated with practicing self medication behavior by Iraqi respondents in Baghdad City.

\section{Materials and Methods}

This study was a community-based, cross-sectional survey conducted in Baghdad, the capital of Iraq, from February to December 2012 to determine self-medication behavior among the general population. The study population consisted of individuals attending the community pharmacy asking for self medicated drugs. Six private pharmacies in six different sectors of Baghdad city participated in this study. These pharmacies were managed by postgraduate pharmacists. This study involved interviewing the patients in these community 
pharmacies. The patients were $\geq 15$ years old and were included in the study after they gave the researchers (pharmacists) a verbal consent. The researcher recorded the information in a previously prepared questionnaire.

The questionnaire was first prepared in English and then translated to Arabic. Each interview took about 5-10 minutes. The questionnaire included close- and openended questions and it consisted of six sections.

First section included questions on sociodemographic characteristics which are age, gender, marital status, employment status and educational level. Second section investigated the frequency of practicing self medication. Third section searched for reasons of taking self medication. Fourth section identified the source of information about the drugs used in self medication. In the fifth and sixth sections, respondents were asked to report the conditions and diseases to be managed with self medication and the drug or drugs used for this purpose.

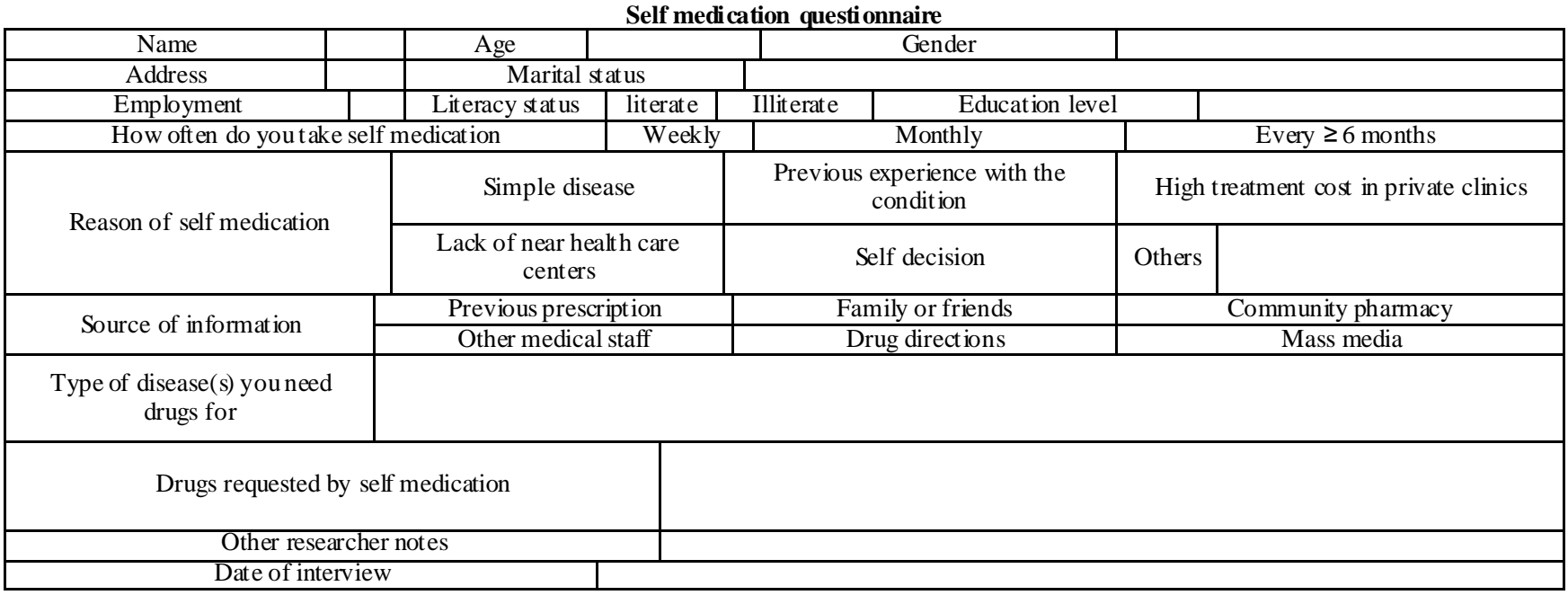

\section{Results}

\subsection{Sociode mographic Characte ristics}

A total of 348 respondents with practice of self medication were included in this study. They were relatively middle aged with an average of $41.9 \pm 12.8$ years with the range of 15-80 years. Of these respondents, 216 were males and 132 were females (62\% versus 38\% respectively). Ages of 250 respondents (71.8\%) were between 30-60 years, sixty four respondents (18.4\%) were aged $15-30$ years and 34 respondents $(9.8 \%)$ were older than 60 years.

Table 1. Sociodemographic characteristics of respondents $(n=348)$

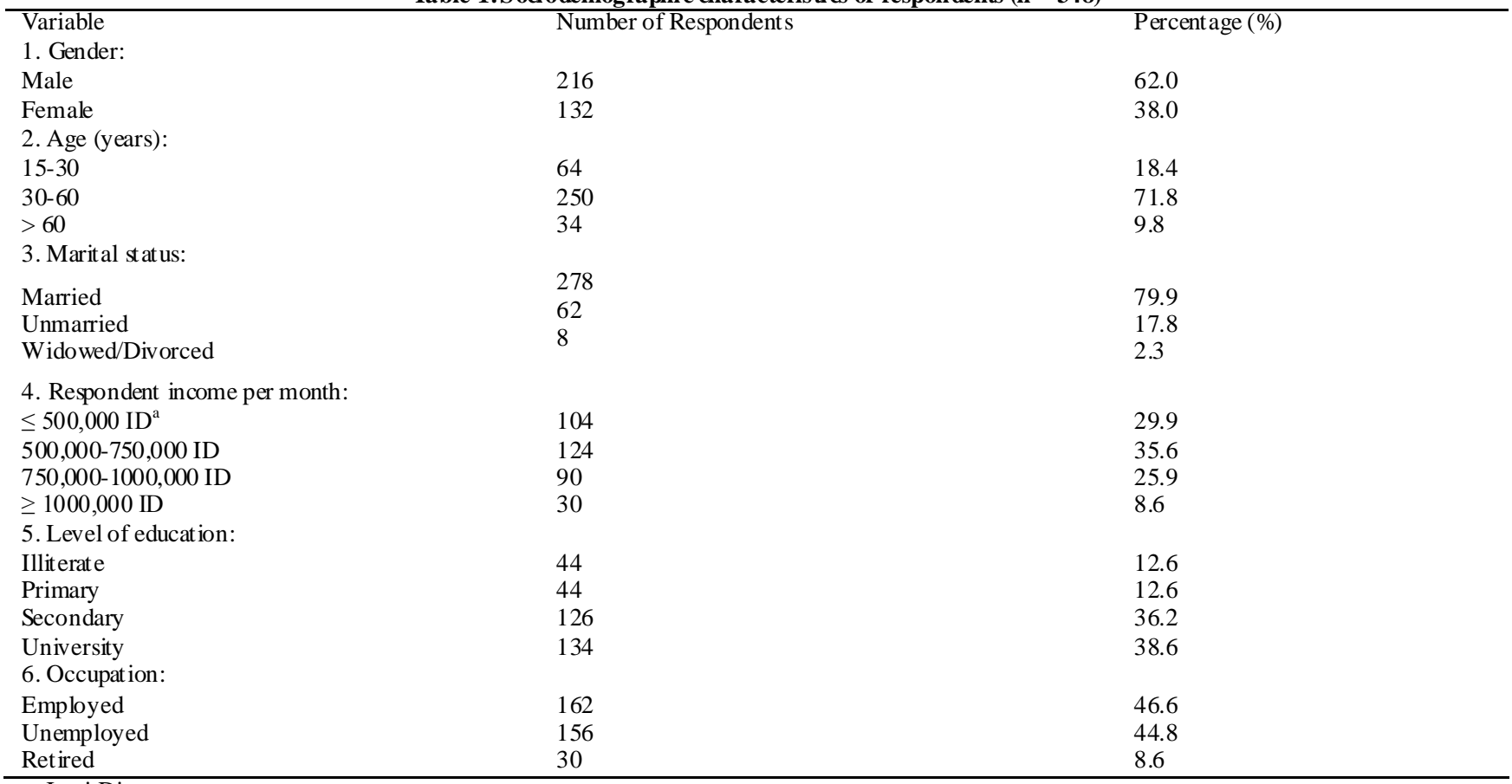

\section{a: Iraqi Dinars}

Regarding marital status, most of the respondents were married [278 respondents (79.9\%)]. About 30\% of the respondents (104 individuals) considered their monthly income less than moderate $(\leq 500,000$ ID), while the rest of respondents ranked their monthly income as moderate or better than moderate level.Only very s mall portion of study population were illiterate [44 respondents (12.6\%)], while the other individuals were literate with most of them 
either fin ished secondary study [126 respondents (36.2\%)] or they were post graduate [134 respondents (38.6\%)].

This study classified the occupation of the respondents into employed, unemployed, and retired. Employed respondents were 162 (46.6\%), unemployed respondents were $156(44.8 \%)$, and the retired respondents were only $30(8.6 \%)$.

\subsection{Self Medication Practice}

Table 2 shows that about 60\% (208 respondents) self medicated at monthly intervals, while $21.3 \%$ (74 respondents) practiced self medication weekly and the remaining 66 respondents (18.9\%) practiced self medication every 6 months or even longer.

Self medicated individuals were asked about the reason behind practicing self medication. The commonest reason reported by two thirds of respondents was no need to see a physician for an ailment previously exposed to and a knowledge was obtained to treat this ailment. Simple condition that could be treated using self medication was reported by 206 individuals (59.2\%). Other reasons included self decision (27.0\%), high cost of consulting a physician in a private clinic (10.3\%), remoteness of health care centers (5.2\%) and the least common reason was chronic or recurrent conditions reported by only 10 respondents $(2.9 \%)$.

This study also investigated the source of information about the drugs used for self medication and found that 212 respondents $(60.9 \%)$ knew about these drugs from a previous prescription, while 180 respondents (51.7\%) got the information from community pharmacists. More than one third of the respondents obtained their information from their parents, relatives, or friends. Other sources of information were another member of health staff $(21.8 \%)$, drug directions $(10.3 \%)$ and the least common was advertis ements or televisions (7.4\%).

Table 2. Frequency of taking self medication, reason for taking self medication and source of information about self medication $(n=348)$

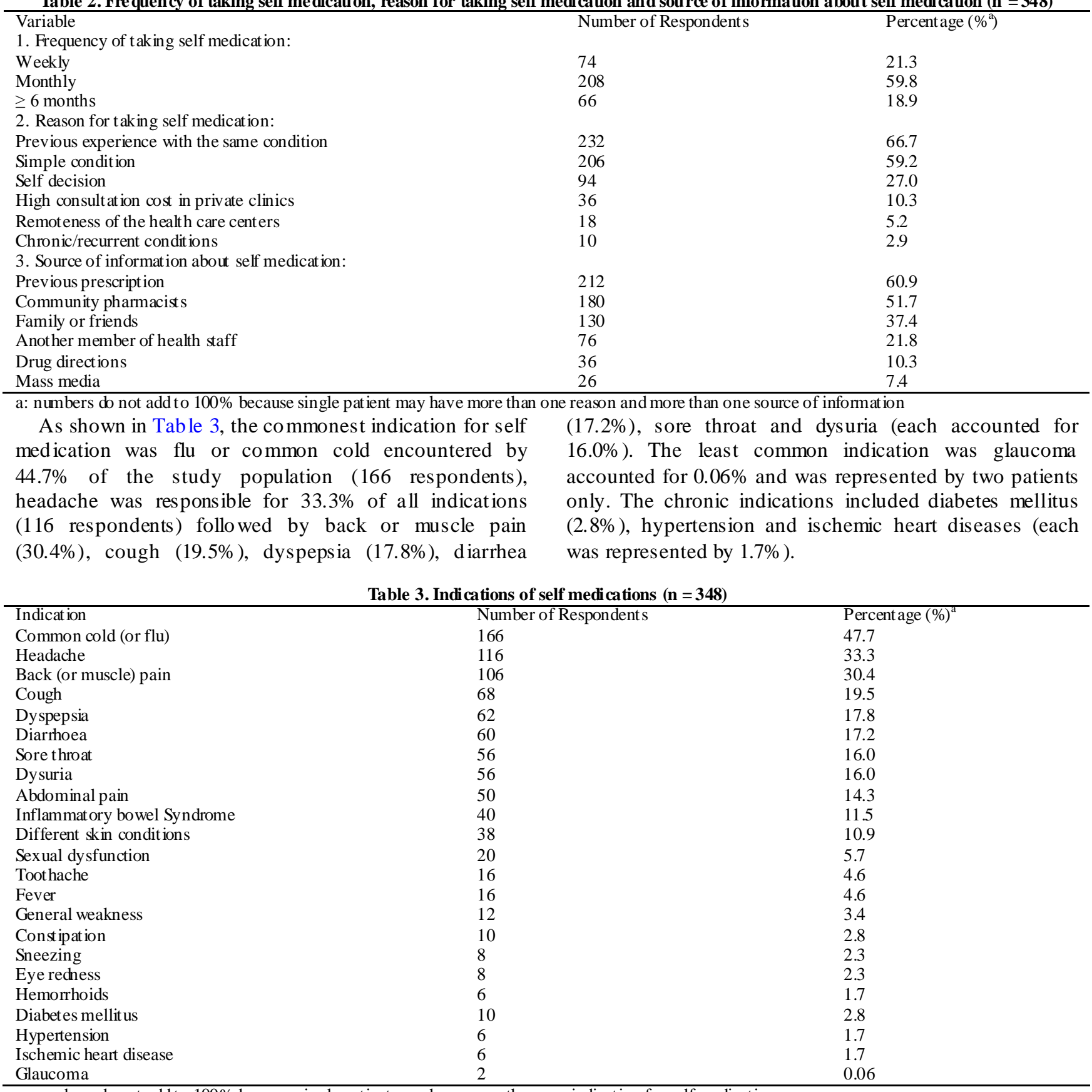

a: numbers do not add to $100 \%$ because single patient may have more than one indication for self medication 
Table 4 demonstrates the drugs used by the respondents for their self medication. The group of antibiotics represented the commonest type of drugs requested by 260 respondents (74.7\%), paracetamol in different preparations was administered by more than half of the respondents (192 respondents) followed by antihistamines (36.2\% or 126 individuals), non-steroidal antiinflammatory drugs (27\% or 94 respondents). Cough preparations accounted for $23.5 \%$ of indications (82 respondents), antispasmodics (22.4\% or 78 respondents), skeletal muscle relaxants ( $16.6 \%$ or 58 respondents), and antacids (14.9\% or 52 respondents). The least commonly used drugs for self medication included diazepam and statin $(1.7 \%$ for each one) and prostaglandin eye drops (0.06\% only).

Table 4. Me dications (drugs) used for self medication

\begin{tabular}{|c|c|c|}
\hline Medication (drug) & Number of Respondents & Percentage (\%) \\
\hline Antibiotics & 260 & 74.7 \\
\hline Paracetamol & 192 & 55.1 \\
\hline Ant ihistamines & 126 & 36.2 \\
\hline NSAID $^{\mathrm{b}}$ & 94 & 27.0 \\
\hline Cough preparations & 82 & 23.5 \\
\hline Antispasmodics & 78 & 22.4 \\
\hline Skeletal muscle relaxant & 58 & 16.6 \\
\hline Ant acids & 52 & 14.9 \\
\hline Antidiarneals & 42 & 12.0 \\
\hline Urine alkalinizer and Ant iseptic & 38 & 10.9 \\
\hline Omeprazole & 32 & 9.1 \\
\hline Multivitamins/minerals & 28 & 8.0 \\
\hline Bisacodyl & 10 & 2.8 \\
\hline Chloramphenicol eye drop & 4 & 1.1 \\
\hline Systemic steroids & 10 & 2.8 \\
\hline Sildenafil & 20 & 5.7 \\
\hline Lozenges & 18 & 5.1 \\
\hline Low dose aspirin & 18 & 5.1 \\
\hline Diazepam & 6 & 1.7 \\
\hline topical skin preparations & 58 & 16.6 \\
\hline Antidiabetic & 18 & 5.1 \\
\hline $\mathrm{ACEI}^{\mathrm{C}}$ & 8 & 2,3 \\
\hline Statins & 6 & 1.7 \\
\hline Prostaglandin eye drop & 2 & 0.06 \\
\hline
\end{tabular}

a: numbers do not add to $100 \%$ because single patient may use more than one medicat ion

b: non-steroidal anti-inflammat ory drugs

c: angiotensin converting enzyme inhibitors

\section{Discussion}

This study was limited to Baghdad because it is the largest city in Iraq according to its population with varying sociodemographic characteristics and also because of financial and time considerations.

Comparing results of this study with those of other studies conducted in other countries seems somewhat difficult due to differences in cultures, health care systems and the roles of community pharmacies. This study found that male respondents practiced self medication to larger extent than females. This result is consistent with the result of another study [13] and contradicts others [14,15]. This result could be attributed to that many females leave homes only with the companionship of a male relative from the first degree. Therefore, females less commonly get their self medications from community pharmacies [13].

This study indicated that about $90 \%$ of study populations were 15-60 years old and this seems logical since these individuals have greater ability than older individuals to move and seek medications due to fewer incidences of having joint or card iovascular diseases than the older persons $[16,17,18]$. In this study, most respondents were married due to religious and traditional considerations which encourage marriage at young ages.

About two thirds of the study population ranked their monthly income less than good income. This result is consistent with other studies conducted in third world countries which found that majority of population practicing self medication were of low economic status $[19,20]$. This study demonstrated that about $87 \%$ of respondents were literate and nearly half of these individuals had an academic certificate. This could be explained by increasing percentage of educated individuals in the general population $[13,21]$.

The main reason of practicing self medication for two thirds of study population was experience and knowledge of treatment from similar previous ailments; this could be explained by the ability of people to remember med ications whether prescribed or over the counter (OTC) used for similar previous conditions especially if these medications were successful in improving such conditions or symptoms [22]. The second major reason mentioned by $59.2 \%$ of respondents was simple ailment which did not require physician consultation; this finding is consistent with results of other study which showed that patients perception of their current conditions as simple conditions to be the dominant cause behind practicing self medication [23]. Other reasons for practicing self medication included high cost of consulting a doctor in a private clinic for $10.3 \%$ of respondents (this factor was especially identified for subjects with relatively low monthly income) and remoteness of health care centers for $5.2 \%$ of study population. Such findings resemble those of previous studies which attributed the self medication phenomenon to its relatively lower costs compared with obtaining medications after consulting a physician especially for those with low economic status who depend principally on primary health care centers for treating their health conditions $[24,25]$. The least common reason was chronic or recurrent conditions because most patients with these 
conditions were supplied with their chronic medications regularly from public health care centers distributed in Baghdad city which supply drugs at lower costs than the private pharmacies.

The most important source of information of self medication reported in this study was previous prescriptions which could be related to the reason of requiring self medications by two thirds of the patients (previous experience with the same condition). The other important source of information represented by $51.7 \%$ of the patients was the community pharmacists; this result agrees with that of previous works and gives an evidence of the importance of community pharmacies in the wide pervasion of self medication practice in the community [24]. This study like others [26] revealed the important roles of other family members and close friends to be a good source of advice about self medicated drugs because some of them experienced similar conditions previously, while others may be physicians, pharmacists or nurses [26]. Medical staff members other than physicians and pharmacists represented the source of information for fifth of the patients due to ease of access and prevalence in Baghdad city. Other less important sources included drug directions (10.3\%) and advertisement via mass media (7.4\%).

The study showed that some conditions treated by self medicated drugs were simple and the patients did not require seeing a doctor for these conditions, but other conditions were different and would otherwise require medical supervision for further evaluation or treatment. It is obvious that flu or common cold were the most common indications of self medication reported by nearly half the patients; the probable explanation of this finding is that the study was done in autumn and winter when the prevalence of these conditions was high $[27,28]$ and because more individuals become well educated about the fact that common cold is a self limiting condition, thus they have the ability to treat it utilizing self medication without the need to see a physician [14]. Other common indications included headache (33.3\%), back or muscle pain (30.4\%), cough (19.5\%), dyspepsia (17.8\%), diarrhea (17.2\%), sore throat $(16.0 \%)$, dysuria $(16.0 \%)$, abdominal pain $(14.3 \%)$ and inflammatory bowel syndrome (11.5\%). These percentages resemble the results of other studies $[1,7,24]$. The least common indications were chronic or recurrent diseases (hypertension, diabetes, ischemic heart diseases and glaucoma) since these patients mostly received their medications from public health care centers as mentioned earlier.

The respondents used many types of drug classes for self medications; some drugs were OTC and could be dispensed according to patients' requests, while other self medicated drugs were prescription only medications and should be dispensed only according to a physician prescription. About three quarters of study population used an antibiotic. This high prevalence resembles others documented among many developing countries like Sudan [24] and Ethiopia [29]. This is largely due to absence of regulations governing the use of antibiotics and due to high rate of using antibiotics without prescription for treating minor illnesses like common cold, cough and sore throat which are mostly viral in nature not requiring antibiotics for treatment [30]. The second most commonly used drug for more than half of respondents was paracetamol because this drug could be administered either alone or in combinations with other drugs for treating various dis orders like headache, flu, common cold, dental pain or muscular pain. Other drugs included antihistamines (36.2\%) followed by non-steroidal antiinflammatory drugs (27.0\%), cough preparations (23.5\%), antispasmodics (22.4\%), skeletal muscle relaxants (16.6\%), antacids (14.9), antid iarrheals (12.0\%) and others These findings may resemble those of other studies which found that analgesic/antipyretic drugs were the commonest drugs used followed by antimicrobials and gastro-intestinal drugs [7] or others which identified the analgesic/antipyretic followed by cough remedies and systemic nasal decongestants to be the commonest self med ication drugs $[31,32]$.

\section{Conclusions}

This study concluded that Iraqi individuals of Baghdad city who practiced self medication were of different sociodemographic characteristics. This study illustrated that many Iraqi patients can easily practice self medication for the management of wide range of conditions whether simple or not. For managing their conditions, these patients can obtain many types of drug classes; even prescription only medications could be dispensed for self medication purposes as well as the OTC drugs.

Therefore, it is strongly recommended to encourage the general population to have greater attendance to primary health care centers and to initiate education programs for them to specify the conditions that could be treated by self medication practice. Other recommendation is to reinforce the drugs which could be dispensed legally and safely from the community pharmacies without a medical supervision. These measures will help to reduce the consequences of either suboptimum or exaggerated treatment of some conditions and in the same time reduce the hazards of misuse or side effects of certain types of drugs. Finally it is recommended to enlarge the study and be conducted in other cities within Iraq to explore the prevalence and the effects of this practice throughout the country.

\section{References}

[1] Ali et al. Self-medication practices among health care professionals in a private university, Malaysia. International Current Phamaceutical Joumal, 1 (10). 302-310. 2012.

[2] Montastruc J.L et al. Pharmacovigilance of self-medication. Therapies, 52 (2). 105-110. 1997.

[3] Guidelines for the regulatory assessment of medicinal products for use in self-medication. Geneva, World Health Organization, (WHO) 2000.

[4] Hayran O, Karavus M, Aksayan S. Help-seeking behavior and self-medication of a population in an urban area in Turkey. Croatian Medical Journal, 41. 327-332. 2000.

[5] Aljinovic, V.V., Trukilja, V. and Lackovic, Z. Content of home pharmacies and self-medication practice in households of pharmacy and medication students in Zagreb, Croatia. Croatian Medical Journal, 46 (1). 74-80. 2005.

[6] Hughes, C.M., McElnay, J.C., and Fleming, G.F. Benefits and risks of self medication. Drug Safety, 24 (14). 1027-1037. 2001.

[7] Pankaj, J., Ajay, S., Rajeev, K., and Pankaj, A. Statistical Study on Self Medication Pattern in Haryana, India. Indo Global Joumal of Pharmaceutical Sciences, 2 (1). 21-35. 2012. 
[8] Fuentes, K.A., Villa, L.Z. Analysis and quantification of selfmedication patterns of customers in community pharmacies in southern Chile. Pharmacy World and Science, 30. 863-868. 2008.

[9] Uehleke, B., Steinhoff, B. Self-medication in Germany. Intemational Joumal of Clinical Phamacology and Therapeutics, 39. 484-487. 2001.

[10] Ebert, S.C. Factors contributing to excessive antimicrobial prescribing. Phamacotherapy, 27.126-130. 2007.

[11] Vila, J., Pal, T Update on antibacterial resistance in low-income countries: Factors favoring the emergence of resistance. Open Infectious Diseases Joumal, 4. 38-54. 2010.

[12] Durgawale, P.M. Practice of self-medication among slum dwellers. Indian Joumal of Public Health, 42 (2). 53-55. 1998.

[13] Alghanim, S.A. Self-medication practice among patients in a public health care system. Eastem Mediterranean Health Joumal, 17 (5). 409-416. 2011.

[14] Chua, S.S, Sabki, N.H. Use of nonprescription medications by the general public in the Klang Valley. Journal of Applied Pharmaceutical Science, 1 (9). 93-98. 2011.

[15] Carrasco, G.P. et al. Pattems of medication use in the immigrant population resident in Spain. Phamacoepidemiology and Drug Safety, 18. 743-750. 2009.

[16] Alan, D.K., Amir, B. and Jared, T.S. Pain management in the elderly population. The Ochsner Journal, 10. 179-187. 2010.

[17] Lakatta, E.G. Age-associated cardiovascular changes in health: impact on cardiovascular disease in older persons. Heart Failure Review, 7 (1). 29-49. 2002.

[18] Brian, J.N, and David, A.S. The Intersection Between Aging and Cardiovascular Disease. Circulation Research, 110, 1097-1108. 2012.

[19] Solomon, W., Abebe, G.M. Practice of Self-medication in Jimma Town. Ethiopian Joumal of Health Development, 17 (2). 111-116. 2003.

[20] Hussain, A. and Khanum, A. Self-medication among university students of Islamabad, Pakistan. Southem Med Review, 1 (1). 1416. 2008.
[21] Aris, W., Sri, S., Charlotte, C., and Janet, E.H. Self medication with antibiotics in Yogyakarta City Indonesia: a cross sectional population-based survey. BMC Research Notes, 4. 491. 2011.

[22] Grigoryan, L., Burgerhof, J.G., Haaijer, F.M, Degener, J.E, Deschepper, R. et al. Is self medication with antibiotics in Europe driven by prescribed use? Joumal of Antimicrobial Chemotherapy, 59 (1). 152-156. 2007.

[23] James, H. et al. Influence of medical training on selfmedication by students. International Joumal of Clinical Phamacology and Therapeutics, 46 (1). 23-29. 2008.

[24] Awad, A.I, Eltayeb, I.B, Capps, P.A. Self-medication practices in Khartoum State, Sudan. European Joumal of Clinical Pharmacology, 62. 317-324. 2006.

[25] Sawalha, A.F. A descriptive study of self-medication practices among Palestinian medical and nonmedical university student. Research in Social and Administrative Pharmacy, 4. 164-172. 2008.

[26] Ghosh, S. et al. Evaluation of the practice of self medication among college students in west Uttar Pradesh. International Journal of Phama Professional's Research, 1 (1). 14-18. 2010.

[27] Christopher, F. The Effects of Weather and Climate on the Seasonality of Influenza: What We Know and What We Need to Know. Geography Compass, 10. 718-730. 2010.

[28] Eccles, R. An Explanation for the Seasonality of Acute Upper Respiratory Tract Viral Infections. Acta Otolaryngol, 122. 183191. 2002.

[29] Tenaw. A., Tsige G.M. Self-medication practices of drug consumers. Ethiopian Journal of Health Science, 14. 1-11. 2004.

[30] McKee, M.D., Mills, L., Mainous, A.G. Antibiotic use for the treatment of upper respirat ory infections in a diverse community. Journal of Family Practice, 48 (12). 993-996. 1999.

[31] Douglas, D., Rybeck, B.F., Tracy, T.S. Medication use in a rural gynecologic population: Prescription, over-the-counter, and herbal medicines. American Journal of Obstetrics \& Gynecology, 190. 351-357. 2004

[32] Sleath, B., Rubin, R.H, Campbell, W., Gwyther, L, Clark, T. Physician-patient communication about over-the-counter medications. Social Science \& Medicine, 53. 357-369. 2001. 